\title{
Sensory Processing Disorders are Associated with Duration of Current Episode and Severity of Side Effects
}

\author{
Gianluca Serafini ${ }^{1} \bowtie$, Batya Engel-Yeger², Gustavo H. Vazquez ${ }^{3,4}$, Maurizio Pompili $^{5}$, and Mario Amore ${ }^{1}$ \\ ${ }^{1}$ Department of Neuroscience, Rehabilitation, Ophthalmology, Genetics, Maternal and Child Health, Section of Psychiatry, University of Genoa, \\ Genoa, Italy \\ ${ }^{2}$ Department of Occupational Therapy, Faculty of Social Welfare and Health Sciences, University of Haifa, Israel \\ ${ }^{3}$ International Consortium for Bipolar \& Psychotic Disorder Research, Department of Psychiatry, Harvard Medical School, Boston, MA, USA \\ ${ }^{4}$ Department of Neuroscience, Palermo University, Buenos Aires, Argentina \\ ${ }^{5}$ Department of Neuroscience, Suicide Prevention Center, Sant'Andrea Hospital, University of Rome, Rome, Italy
}

Objective Longer duration of untreated illness, longer duration of current episode, and the severity of medication side effects may negatively impact on the perceived disability and psychosocial impairment of patients with major affective and anxiety disorders. Studies also suggested the involvement of sensory perception in emotional and psychopathological processes. The present study aimed to examine the relationship between Sensory Processing Disorders (SPD), duration of untreated illness and current illness episode, and the severity of side effects related to psychoactive medications.

Methods The sample included 178 participants with an age ranging from 17 to 85 years $($ mean $=53.84 \pm 15.55)$. Participants were diagnosed with unipolar Major Depressive Disorder (MDD) (50\%), Bipolar Disorder (BD) (33.7\%), and Anxiety disorders (16.3\%). They completed a socio-demographic questionnaire, the Udvalg for Kliniske Undersøgelser (UKU), and Adolescent/Adult Sensory Profile (AASP) questionnaire.

Results Longer duration of current episode correlated with greater registration of sensory input and lower avoidance from sensory input among unipolar patients; with lower registration of sensory input, and higher tendency for sensory sensitivity/avoidance among bipolar participants; with lower sensory sensitivity/avoidance among anxiety participants, respectively. Also, mean UKU total scores correlated with lower sensory sensitivity among bipolar individuals.

Conclusion SPD expressed in either hypo/hyper sensitivity may serve to clinically characterize subjects with major affective and anxiety disorders. Psychiatry Investig 2017;14(1):51-57

Key Words Major affective disorders, Anxiety disorders, Sensory processing disorders, Sensation seeking, Hypersensitivity.

\section{INTRODUCTION}

Patients with major affective and anxiety disorders frequently experience psychosocial impairment and multiple dysfunctions. ${ }^{1-3}$ Psychoactive medications together with other treatment options are commonly used to minimize, at least partially, these negative outcomes in major psychiatric conditions.

Given the detrimental consequences of these disabling con-

Received: December 23, 2015 Revised: February 16, 2016

Accepted: February 16, 2016 Available online: June 1, 2016

$\triangle$ Correspondence: Gianluca Serafini, MD, PhD

Department of Neuroscience, Rehabilitation, Ophthalmology, Genetics, Maternal and Child Health (DINOGMI), Section of Psychiatry, University of Genoa, IRCCS San Martino, Largo Rosanna Benzi 10, 16132, Genoa, Italy Tel: +390103537668, Fax: +390103537669, E-mail: gianluca.serafini@unige.it (a) This is an Open Access article distributed under the terms of the Creative Commons Attribution Non-Commercial License (http://creativecommons.org/licenses/bync/3.0) which permits unrestricted non-commercial use, distribution, and reproduction in any medium, provided the original work is properly cited. ditions either at individual and social levels, researchers are encouraged to identify factors that may help to better predict illness trajectories as well as early management and adequate treatment.

Studies highlighted the involvement of sensory perception in emotional processes. It has been suggested that Sensory Processing Disorders (SPD) may be significantly involved in psychopathological processes and directly contribute to impaired daily functioning. ${ }^{4,5}$ The term "sensory intolerance" has been recently used in the current literature ${ }^{6}$ and is also recognized as SPD. SPD encompass difficulties in registering and modulating sensory information and organizing sensory input to perform successful adaptive responses to situational demands. ${ }^{7,8}$ Hyposensitivity may be expressed by either a pattern of low registration in which individuals fail to detect sensation and do not actively seek for sensory input, or sensation seek- 
ing in which individuals enjoy rich and intensive sensory environments and activities. Conversely, hypersensitivity, expressed in either a pattern of sensory sensitivity in which individuals feel discomfort with regular sensations but do not actively limit their exposure to them, or sensation avoidance in which people actively limit exposure to unpleasant sensations. $^{9}$

Evidence also suggested the importance to identify the main predictors associated with a poor outcome in patients with anxiety and affective disorders. Longer duration of illness episodes have been associated with higher recurrences of the illness and chronicity ${ }^{10,11}$ which are related, in turn, with higher social/functional impairments ${ }^{12,13}$ as well as poorer response to treatment ${ }^{14-16}$ when compared with less persistent illness episodes. Furthermore, a delay in initiating treatments has been suggested as one of the most relevant predictor of non-response to treatments and poor functional outcome. ${ }^{17,18}$

Similarly, the severity of side effects has been reported as a predictor of poor treatment adherence negatively influencing the long-term outcome of patients with major affective disorders ${ }^{19,20}$ and potentially enhancing treatment resistance as well as the neurobiological sequelae associated with the illness. ${ }^{21}$

However, although their influence on the outcome of patients with anxiety and affective disorders has been widely demonstrated, the relationship between SPD, duration of untreated illness and current illness episode together with severity of side effects related to psychoactive medications has not been systematically investigated.

Here, we aimed to investigate the association between SPD, duration of untreated illness and current illness episode as well as severity of medications side effects in a sample of psychiatric outpatients. Based on previous studies examining the impact of SPD and sensory over-responsivity in healthy young individuals, ${ }^{9,22,23}$ adults $^{22-25}$ and different populations of patients (e.g., children with disabilities or healthy individuals), ${ }^{26-29}$ we hypothesized that the longer duration of current illness episode and untreated illness together with the higher severity of medications side effects may correlate with specific SPD patterns.

\section{METHODS}

\section{Sample}

The sample included 178 participants with an age ranging from 17 to 85 years $($ mean $=53.84 \pm 15.55)$. Participants were distributed as follows: $50 \%$ of them were diagnosed with unipolar Major Depressive Disorder (MDD), 33.7\% with Bipolar Disorder (BD) type I and type II, and 16.3\% with Anxiety disorders (AD). All participants were consecutively admitted to the Department of Neuroscience (DINOGMI), University of
Genoa, between July and December 2014. Psychiatric histories were carefully collected using all the available cross-sectional and retrospective information: medical records, information from the treatment team, and additional information from family or friends. All subjects were diagnosed using the Diagnostic and Statistical Manual of Mental Disorders criteria (DSM-IV, TR) ${ }^{30}$ and the Mini International Neuropsychiatric Interview (MINI). ${ }^{31}$ Exclusion criteria were any conditions affecting the ability to fill out the assessment, including delirium, dementia or any severe neurological diseases, and denial of the informed consent. Significant discrepancies between these sources served as further criteria for exclusion from the study. All the patients accepted voluntarily to participate in the study and gave regularly their informed consent. The study design was approved by the local ethical review board. Table 1 summarizes the most relevant participants' socio-demographic and health related information in each diagnostic group.

\section{Measures}

Demographic questionnaire. In this self-report questionnaire respondents answered questions about: health status, socio-demographic status, psychoactive and non-psychoactive medications.

The Adolescent/Adult Sensory Profile (AASP) ${ }^{32}$ is a selfmeasure psychometric tool with 60 items, sorted into four patterns reflecting Dunn's model. ${ }^{9}$ Participants indicate the frequency of their behavioural responses to sensory experiences in daily life on a five-point Likert scale. In the present study, the five ranges for each sensory processing pattern, as presented in the AASP manual were merged into: 1) "Less than most people" [representing approximately $16 \%$ of the population, or more than one standard deviation (SD) below the mean]; 2) "Similar to most people" (representing approximately $68 \%$ of the population between -1 SD and +1 SD); 3) "More than most people" (representing approximately 16\% of the population, or more than $1 \mathrm{SD}$ above the mean). The AASP is currently under validation in Italian language.

The Udvalg for Kliniske Undersøgelser (UKU) measured pharmacological treatment side effects and their severity. ${ }^{33}$ The severity and the perception or assessment that a symptom is a side effect was assessed as follows: $0=$ no, $1=$ mild, $2=$ moderate, $3=$ severe side effect. The UKU Scale is divided into four sections evaluating psychiatric symptoms (10 items), neurological symptoms (8 items), autonomic symptoms (11 items), and other effects (19 items), respectively.

Current episode duration/duration of untreated illness. Current episode duration has been measured by clinicians in days whereas duration of untreated illness has been retrospectively retraced in years based on the clinical history. 
Table 1. Participants' socio-demographic information in each group

\begin{tabular}{|c|c|c|c|}
\hline Socio-demographic information & Unipolar $(\mathrm{N}=89), \%$ & Bipolar $(\mathrm{N}=60), \%$ & Anxiety $(\mathrm{N}=29), \%$ \\
\hline \multicolumn{4}{|l|}{ Gender } \\
\hline Male & 32.6 & 35 & 41.4 \\
\hline Female & 67.4 & 65 & 58.6 \\
\hline \multicolumn{4}{|l|}{ Level of education } \\
\hline Elementary schools & 7.9 & 8.3 & 3.4 \\
\hline Junior high schools & 32.6 & 30 & 41.4 \\
\hline Secondary schools & 52.8 & 43.3 & 51.7 \\
\hline Academy & 6.7 & 18.3 & 3.4 \\
\hline \multicolumn{4}{|l|}{ Marital status } \\
\hline Single & 30.3 & 28.3 & 48.3 \\
\hline Married & 46.1 & 58.3 & 31 \\
\hline Divorced & 13.5 & 11.7 & 17.2 \\
\hline Widowed & 10.1 & 1.7 & 3.4 \\
\hline \multicolumn{4}{|l|}{ Living with } \\
\hline Alone & 22.5 & 15 & 31 \\
\hline Family & 73 & 83.3 & 65.5 \\
\hline Friend & 4.5 & 1.7 & 3.4 \\
\hline Missing & 0 & 0 & 0 \\
\hline \multicolumn{4}{|l|}{ Employment } \\
\hline Employed & 39.3 & 46.7 & 44.8 \\
\hline Unemployed & 27 & 26.7 & 31 \\
\hline Retired & 31.5 & 26.7 & 20.7 \\
\hline Student & 1.1 & 0 & 3.4 \\
\hline Missing & 1.1 & 0 & 0 \\
\hline \multicolumn{4}{|l|}{ Socio-economic status } \\
\hline Below average & 39.3 & 45 & 58.6 \\
\hline Average & 55.1 & 46.7 & 41.4 \\
\hline Above average & 5.6 & 8.3 & 0 \\
\hline \multicolumn{4}{|c|}{ Significant distressing life events in the last 6 months } \\
\hline No & 50.6 & 80 & 79.3 \\
\hline Yes & 48.3 & 20 & 20.7 \\
\hline Missing & 1.1 & 0 & 0 \\
\hline \multicolumn{4}{|l|}{ Age of illness onset } \\
\hline Range & $10-85$ & $8-56$ & $13-78$ \\
\hline Mean \pm SD & $47.54 \pm 16.21$ & $32.03 \pm 12.75$ & $44.79 \pm 17.02$ \\
\hline \multicolumn{4}{|l|}{ Illness duration in years } \\
\hline Range & $0.3-60$ & $0.5-65$ & $0.5-52$ \\
\hline Mean \pm SD & $11.36 \pm 15.26$ & $19.82 \pm 17.74$ & $10.13 \pm 13.73$ \\
\hline \multicolumn{4}{|l|}{ Subjects who use antidepressants } \\
\hline Mean & 39.3 & 15.2 & 12.9 \\
\hline \multicolumn{4}{|l|}{ Subjects who use mood stabilizers } \\
\hline Mean & 7.3 & 24.1 & 3.9 \\
\hline \multicolumn{4}{|l|}{ Subjects who use antipsychotic agents } \\
\hline 1st generation & 2.2 & 2.5 & 0 \\
\hline 2nd generation & 5 & 9.5 & 3.4 \\
\hline \multicolumn{4}{|l|}{ Subjects who use benzodiazepines } \\
\hline Mean & 30.3 & 16.8 & 14 \\
\hline
\end{tabular}

SD: standard deviation 


\section{Statistical analysis}

All the analyses were performed using the Statistical Package for Social Sciences (SPSS) for Windows 19.0. The correlations between all dependent variables were examined by Pearson correlation test. $p$ values $\leq 0.05$ were considered statistically significant.

\section{RESULTS}

\section{Frequency of SPD as presented by the percentage of participants in each sensory processing performance range for every diagnostic group}

As presented in Table 2, low registration was found under norm (16\% according to the AASP manual) almost 2-3 times more frequently among individuals with unipolar and anxiety disorders $(25.8 \%, 44.8 \%$, respectively).

Seeking was found under norm mostly among individuals with unipolar disorders $(74.2 \%)$ although the percentage of individuals with bipolar and anxiety disorders in this interval was also relatively 3-4 higher than in the general population.

Greater sensitivity was found among individuals with bi-

Table 2. Frequency (in percentage) of participants in each sensory processing pattern for every group

\begin{tabular}{lccc}
\hline & $\begin{array}{c}\text { Unipolar } \\
(\mathrm{N}=89)\end{array}$ & $\begin{array}{c}\text { Bipolar } \\
(\mathrm{N}=60)\end{array}$ & $\begin{array}{c}\text { Anxiety } \\
(\mathrm{N}=29)\end{array}$ \\
\hline Low registration & & & \\
$\quad$ Under norm & 25.8 & 18.3 & 44.8 \\
Norm & 47.2 & 41.7 & 44.8 \\
Above norm & 23.6 & 30 & 10.4 \\
Missing & 3.4 & 10 & \\
Seeking & & & \\
Under norm & 74.1 & 51.6 & 69 \\
Norm & 19.1 & 31.7 & 27.6 \\
Above norm & 3.4 & 1.7 & 0 \\
Missing & 3.4 & 15 & 3.4 \\
Sensory sensitivity & & & \\
Under norm & 19.1 & 8.3 & 17.2 \\
Norm & 49.4 & 43.3 & 55.2 \\
Above norm & 28.1 & 35 & 24.1 \\
Missing & 3.4 & 13.3 & 3.4 \\
Sensory avoidance & & & \\
Under norm & 16.9 & 15 & 20.7 \\
Norm & 52.8 & 41.7 & 58.6 \\
Above norm & 25.8 & 31.7 & 17.2 \\
Missing & 4.5 & 11.6 & 3.4 \\
\hline More than mostpeple: & 549.6 & \\
\hline
\end{tabular}

More than most people: one standard deviation above AASP normal range, Similar to most people: similar to AASP normal range, less than most people: one standard deviation below AASP normal range. AASP: Adolescent/Adult Sensory Profile polar disorders (35\%), however the percentage of individuals with unipolar and anxiety disorders above the norms, was also relatively high (28.1\%, $24.1 \%$ respectively). A similar trend (bipolar: $25.8 \%$, unipolar: $31.7 \%$, anxiety: $17.2 \%$ ) was found in regard to sensation avoiding.

\section{Correlations between SPD, duration of untreated illness, and duration of current episode}

As presented in Table 3, among unipolar participants, longer duration of current episode (days) significantly correlated with greater registration of sensory input $(\mathrm{r}=-0.25 ; \mathrm{p}=0.02)$ and lower avoidance from sensory input. Among bipolar participants, an opposite direction was found: longer duration of current episode (days) significantly correlated with lower registration of sensory input $(\mathrm{r}=0.28 ; \mathrm{p}=0.04)$, greater tendency for sensory sensitivity $(\mathrm{r}=0.28 ; \mathrm{p}=0.04)$ and sensation avoidance $(\mathrm{r}=0.28 ; \mathrm{p}=0.03)$. Among participants with anxiety disorders, longer duration of current episode (days) significantly correlated with lower sensory sensitivity/avoidance $(r=-0.49$; $\mathrm{p}=0.01 ; \mathrm{r}=-0.42 ; \mathrm{p}=0.01$, respectively).

\section{Correlation between SPD and severity of medication side effects}

Among bipolar participants, mean UKU score correlated with lower sensory sensitivity $\left(\mathrm{r}=-0.31,{ }^{*} \mathrm{p} \leq 0.05\right)$ indicating that among these patients higher is UKU, the lower is the sensory sensitivity.

\section{DISCUSSION}

This is the first study aimed to investigate the association between SPD, duration of untreated illness and current illness episode, as well as severity of medications side effects in a sample of psychiatric outpatients. The prevalence of SPD among patients with major affective and anxiety disorders was mainly expressed in elevated sensory sensitivity/avoidance, low registration, and lower tendency for sensation seeking. While an extremely higher percentage of individuals was reported in all three groups in regard to lower tendency for sensation seeking, these trends were much more prevalent $(69 \%, 44.8 \%$, respectively) among subjects with anxiety. This may be related to the greater sensitivity and avoidance of these patients. Similar results were found in the study of Engel-Yeger and Dunn ${ }^{23}$ on healthy adults in which sensory sensitivity/avoidance profiles but also lower registering were related to enhanced anxiety trait. The authors suggested that lower registrators tend to miss sensory stimuli but once they do notice, they are overwhelmed.

Unipolar patients showed similar SPD trends as patients with anxiety disorders. Bipolar patients showed the highest 
Table 3. Correlations between SPD, duration of untreated illness and of current episode, and medication side effects in each group

\begin{tabular}{ccccc}
\hline Sensory profiles & Low registration & Sensation seeking & Sensory sensitivity & Sensation avoiding \\
\hline Duration of current episode (days) & $-0.25^{*}$ & NS & NS & $-0.27^{*}$ \\
& $0.28^{*}$ & NS & $0.28^{*}$ & $0.28^{*}$ \\
Duration of untreated illness (years) & NS & NS & $-0.49^{* *}$ & $-0.42^{*}$ \\
& NS & NS & NS & NS \\
Mean UKU & NS & NS & NS & NS \\
& NS & NS & NS & NS \\
& NS & NS & $-0.31^{*}$ & NS \\
\hline
\end{tabular}

Unipolar ( $\mathrm{N}=83)$, bipolar $(\mathrm{N}=54)$, anxiety $(\mathrm{N}=26) .{ }^{*} \mathrm{p} \leq 0.05,{ }^{* *} \mathrm{p} \leq 0.01$. NS: not significant, $\mathrm{SPD}$ : sensory processing disorders, UKU: Udvalg for Kliniske Undersøgelser

prevalence of subjects with sensation avoidance and sensitivity. Overall, this supports previous reports about the elevated vulnerability of patients with major affective and anxiety disorders to impaired modulation of sensory input ${ }^{34}$ but also suggests that the expression of SPD in specific affective conditions may be slightly different.

Hence, clinicians may use sensory profiles in order to better understand mechanisms involved throughout the course of psychiatric disease. For example, it is known that sensory hypersensitivity might be an unrecognized contributing factor for anxiety and may exaggerate emotional related outcomes such as negative emotionality ${ }^{35}$ and depression. ${ }^{36}$ This trend may be more problematic when combined with lower seeking and registration of sensory input. Indeed, these individuals may not actively seek for sensations in order to avoid them, as a coping mechanism. Reduced seeking and registration have been also related to depression, social isolation, impaired physical, cognitive and emotional status, ${ }^{37}$ impaired general health, ${ }^{38}$ and reduced participation in daily life activities. ${ }^{39} \mathrm{~A}$ better understanding of this fundamental topic could provide insights into whether the reported patient difficulties may reflect a specific emotional deficit or rather a generalized sensory processing problem. ${ }^{40}$

The above findings stress the need to refer to the SPD and their possible negative impacts on the individuals' daily life but also refer to the possible interaction between SPD and clinical characteristics. The importance to identify the main predictors associated with a poor outcome in patients with anxiety and affective disorders is well known. In this regard, one of the most interesting variable which has been repeatedly investigated was duration of current illness episode. We found that among bipolar patients, longer duration of episode correlated with lower registration and greater sensitivity/avoidance whereas we did not find any significant correlation between longer duration of untreated illness and SPD. An opposite trend was found among unipolar patients (where longer duration of episode correlated with greater registration and great- er avoidance) and patients with anxiety with regard to greater sensitivity/avoidance.

Individuals with lower registration fail to detect sensation and do not actively seek for sensory input whereas individuals who actively limit exposure to sensations use strategies to avoid the unpleasant sensory experience and negative outcomes. ${ }^{9}$ SPD may predispose bipolar subjects to develop a variety of occasionally maladaptive coping strategies in order to balance the disequilibrium resulting from the inability to integrate information. ${ }^{41}$ Bipolar patients may be defined in our study as a more vulnerable subgroup of subjects who are more likely to exhibit maladaptive coping strategies and a poorer psychosocial adjustment/participation in daily life activities based on their SPD when compared with other groups.

Another interesting finding was that the severity of medication side effects (measured by mean UKU score) correlated with lower sensory sensitivity only among bipolar participants; therefore the higher is the UKU mean total score, the lower is the sensory sensitivity.

To our knowledge, there are no previous studies in the literature about the predictive potential of sensory patterns to distinguish between individuals with higher or lower perceived severity of side effects related to psychoactive treatments. According to our findings, patients with lower sensory sensitivity (bipolar subjects in this study) may be more likely to experience higher severity of side effects related to medications but it's important to note that these individuals may also present an increased likelihood of perceiving these side effects. Bipolar subjects also showed a higher prevalence of hypersensitivity (above 30\% for sensitivity and avoidance). Hypersensitivity is known to be related to greater somatization, greater intensification of pain, ${ }^{22}$ hypervigilance, increased level of attention and arousal, ${ }^{42}$ all of which may significantly impact on the perceived severity of medications side effects. Side effects that significantly enhance functional limitations should be early recognized by clinicians in order to avoid significant distress. Also, the optimized selection of psychoactive medi- 
cations which takes adequately into account the perceived subjective severity of medications side effects may directly impact on treatment adherence. ${ }^{43,44}$ However, this is a complex issue that should be further investigated by prospective studies recruiting larger samples.

In summary, the results of the present study suggest that subjects with major affective and anxiety disorders commonly suffer from SPD that may be associated with specific clinical characteristics which are able to influence the perceived disability and long-term course of the illness. A better understanding of the impact of SPD on daily life of patients with major affective and anxiety disorder may contribute to research and practice related to these patients improving possible intervention benefits as well as quality of life.

Our results should be interpreted in the light of the following limitations. First, the number of participants was relatively low and the study may be underpowered. Thus, the results should be replicated in further larger samples. The cross-sectional study design with the observed associations do not represent causal relationships between the investigated parameters as well. Second, all patients have been selected as outpatients. In addition, given the great variability among participants, it would have been helpful to control for possible confounding socio-demographic variables. Unfortunately, we were not able to control for possible confounders such as age, socio-economic status, age of illness onset, and illness duration. Finally, the possible confounding effect of psychoactive medications (e.g., antidepressants, mood-stabilizers, antipsychotics, and benzodiazepines) was not analyzed. In this regard, it's also important to note that medications side effects should be considered as not specific, since all patients were taking multiple psychoactive medications. However, patients were all consecutive outpatients who had visited our hospital for at least 6 months and whose medication regimens had been stable for at least 6 months prior to recruitment. Moreover, psychoactive medications seem to not significantly affect sensory processing patterns who are supposed to be not state-related but rather stable patterns over the lifespan. ${ }^{45}$

In conclusion, this is, to our knowledge, the first preliminary study examining the association of SPD with clinical variables of patients with major affective and anxiety disorders and its impact on the long term course. Importantly, in addition to the frequent reports of hypersensitivity, we stressed the negative impact of hyposensitivity in subjects with major affective and anxiety disorders, in particular when related to lower registration, or alternatively the resilient role of SPD when referring to sensory seeking. According to our recent published studies, ${ }^{46,47}$ the inclusion of measures of sensory processing patterns may provide relevant insights into the multiple determinants involved in the emer- gence/maintenance of major affective disorders.

\section{REFERENCES}

1. Smith L, Hill N, Kokanovic R. Experiences of depression, the role of social support and its impact on health outcomes. J Ment Health 2015; 24:342-346.

2. Lam RW, Michalak EE, Bond DJ, Tam EM, Axler A, Yatham LN. Which depressive symptoms and medication side effects are perceived by patients as interfering most with occupational functioning? Depr Res Treat 2012;2012:630206.

3. Revicki DA, Travers K, Wyrwich KW, Svedsäter H, Locklear J, Mattera MS, et al. Humanistic and economic burden of generalized anxiety disorder in North America and Europe. J Affect Disord 2012;140:103-112.

4. Pourtois G, Schettino A, Vuilleumier P. Brain mechanisms for emotional influences on perception and attention: what is magic and what is not. Biol Psychol 2013;92:492-512.

5. Portas CM, Krakow K, Allen P, Josephs O, Armony JL, Frith CD. Auditory processing across the sleep-wake cycle: simultaneous EEG and fMRI monitoring in humans. Neuron 2000;28:991-999.

6. Taylor S, Conelea CA, McKay D, Crowe KB, Abramowitz JS. Sensory intolerance: latent structure and psychopathologic correlates. Compr Psychiatry 2014;55:1279-1284.

7. Humphry R. Young children's occupations: explicating the dynamics of developmental processes. Am J Occup Ther 2002;56:171-179.

8. Miller LJ, Anzalone ME, Lane SJ, Cermak SA, Osten ET. Concept evolution in sensory integration: a proposed nosology for diagnosis. Am J Occup Ther 2007;61:135-140.

9. Dunn W. The impact of sensory processing abilities on the daily lives of young children and their families: a conceptual model. Infant Young Child 1997;9:23-35.

10. Keller MB. Depression: a long-term illness. Br J Psychiatry 1994;165 (Suppl 26):9-15.

11. Keller MB, Lavori PW, Mueller TI, Endicott J, Coryell W, Hirschfeld RM, et al. Time to recovery, chronicity and levels of psychopathology in major depression. Arch Gen Psychiatry 1992;49:809-816.

12. Coryell W, Scheftner W, Keller M, Endicott J, Maser J, Klerman GL. The enduring psychosocial consequences of mania and depression. Am J Psychiatry 1993;150:720-727.

13. Judd LL, Akiskal HS, Paulus MP. The role and clinical significance of subsyndromal depressive symptoms (SSD) in unipolar major depressive disorder. J Affect Disord 1997;45:5-17.

14. Cassano GB, Savino M. Chronic and residual major depressions. In: Akiskal HS, Cassano GB, editors. Dysthymia and the spectrum of chronic depressions. New York: Guilford Press; 1997. p.54-65.

15. Perugi G, Medda P, Zanello S, Toni C, Cassano GB. Episode length and mixed features as predictors of ECT nonresponse in patients with medication-resistant major depression. Brain Stimul 2012;5:18-24.

16. Savino M, Perugi G, Musetti L, Soriani A, Mignani V, Cassano GB. La depressione maggiore cronica: caratteristiche diagnostiche e cliniche. In: Pancheri P, Reda GC, editors. Progressi in Psichiatria. Roma: CIC Edizioni Internazionali; 1989. p.1401-1450.

17. Berman RM, Narasimhan M, Charney DS. Treatment refractory depression: definitions and characteristics. Depress Anxiety 1997;5:154-164.

18. Sackeim HA. The definition and meaning of treatment resistant depression. J Clin Psychiatry 2001;62(Suppl 16):10-17.

19. Fawzi W, Abdel Mohsen MY, Hashem AH, Moussa S, Coker E, Wilson KC. Beliefs about medications predict adherence to antidepressants in older adults. Int Psychogeriatr 2012;24:159-169.

20. Pompili M, Venturini P, Palermo M, Stefani H, Seretti ME, Lamis DA, et al. Mood disorders medications: predictors of nonadherence - review of the current literature. Expert Rev Neurother 2013;13:809-825.

21. Bennabi D, Aouizerate B, El-Hage W, Doumy O, Moliere F, Courtet P, et al. Risk factors for treatment resistance in unipolar depression: a systematic review. J Affect Disord 2015;171:137-141. 
22. Engel-Yeger B, Dunn W. The relationship between sensory processing patterns and pain catastrophizing level in healthy adults. Am J Occup Ther 2011a;65:e1-e10.

23. Engel-Yeger B, Dunn W. Exploring the relationship between affect and sensory processing patterns in adults. Br J Occup Ther 2011b;74:456-464.

24. Kinnealey M, Koenig KP, Smith S. Relationships between sensory modulation and social supports and health related quality of life. Am J Occup Ther 2011;65:320-327.

25. Ben-Avi N, Almagor M, Engel-Yeger B. Sensory processing difficulties and interpersonal relationships in adults: an exploratory study. Psychology 2012;3:70-77.

26. Green S, Ben-Sasson A. Anxiety disorders and sensory over-responsivity in children with autism spectrum disorders: is there a causal relationship? J Autism Dev Disord 2010;40:1495-1504.

27. Baker AEZ, Lane A, Angley MT, Young RL. The relationship between sensory processing patterns and behavioural responsiveness in autistic disorder: a pilot study. J Autism Dev Disord 2008;38:867-875.

28. Pfeiffer B, Kinnealey M, Reed C, Herzberg G. Sensory modulation and affective disorders in children with Asperger Syndrome. Am J Occup Ther 2005;59:335-345.

29. Baranek GT. Autism during infance: a retrospective vieso analysis of sensory-motor and social behaviors at 9-12 months of age. J Autism Dev Disord 1999;29:213-224.

30. American Psychiatric Association. Diagnostic and statistical manual of mental disorders DSM-IV-TR. Washington, DC: American Psychiatric Association; 2000.

31. Sheehan DV, Lecrubier Y, Sheehan KH, Amorim P, Janavs J, Weiller E, et al. The Mini-International Neuropsychiatric Interview (M.I.N.I.): the development and validation of a structured diagnostic psychiatric interview for DSM-IV and ICD-10. J Clin Psychiatry 1998;59:22-33.

32. Brown C, Dunn W. The Adolescent/Adult Sensory Profile: user's manual. San Antonio, TX: The Psychological Corporation; 2002.

33. Lingjaerde O, Ahlfors UG, Bech P, Dencker SJ, Elgen K. The UKU side effect rating scale. A new comprehensive rating scale for psychotropic drugs and a cross-sectional study of side effects in neuroleptic-treated patients. Acta Psychiatr Scand 1987;(Suppl 334):1-100.

34. Killgore WD, Britton JC, Schwab ZJ, Price LM, Weiner MR, Gold AL, et al. Cortico-limbic response to masked affective faces across PTSD, panic disorder and specific phobia. Depress Anxiety 2014;31:150-159.

35. Ben-Sasson A, Cermak SA, Orsmond GI, Tager-Flusberg H, Kadlec MB, Carter AS. Sensory clusters of toddlers with autism spectrum disorders: differences in affective symptoms. J Child Psychol Psychiatry
2008;49:817-825

36. Tsuji H, Miyawaki D, Kawaguchi T, Matsushima N, Horino A, Takahashi K, et al. Relationship of hypersensitivity to anxiety and depression in children with high-functioning pervasive developmental disorders. Psychiatry Clin Neurosci 2009;63:195-201.

37. Anstey KJ, Luszcz MA, Giles LC, Andrews GR. Demographic, health, cognitive, and sensory variables as predictors of mortality in very old adults. Psychol Aging 2001;16:3.

38. Pate RR, Pratt M, Blair SN, Haskell WL, Macera CA, Bouchard C, et al. Physical activity and public health. A recommendation from the Centers for Disease Control and Prevention and the American College of Sports Medicine. JAMA 1995;273:402-407.

39. Engel-Yeger B. Validating the Adolescent/Adult Sensory Profile and examine its ability to screen sensory processing difficulties among Israeli people. Br J Occup Ther 2012;75: 321-329.

40. Van Rheenen TE, Rossell SL. Auditory-prosodic processing in bipolar disorder; from sensory perception to emotion. J Affect Disord 2013; 151:1102-1107.

41. Gal E, Dyck MJ, Passmore A. Relationships between stereotyped movements and sensory processing disorders in children with and without developmental or sensory disorders. Am J Occup Ther 2010;64: 453-461.

42. Kinnealey M, Fuiek M. The relationship between sensory defensiveness, anxiety, depression and perception of pain in adults. Occup Ther Int 1999;6:195-206.

43. Sierra Hernandez CA, Oliffe JL, Joyce AS, Söchting I, Ogrodniczuk JS. Treatment preferences among men attending outpatient psychiatric services. J Ment Health 2014;23:83-87.

44. Brown C, Battista DR, Bruehlman R, Sereika SS, Thase ME, DunbarJacob J. Beliefs about antidepressant medications in primary care patients: relationship to self-reported adherence. Med Care 2005;43: 1203-1207.

45. Freedman R, Adler LE, Waldo M. Gating of the auditory evoked potential in children and adults. Psychophysiology 1987;24:223-227.

46. Engel-Yeger B, Muzio C, Rinosi G, Solano P, Geoffroy PA, Pompili M, et al. Extreme sensory processing patterns and their relation with clinical conditions among individuals with major affective disorders. Psychiatry Res 2016;236:112-118.

47. Engel-Yeger B, Gonda X, Muzio C, Rinosi G, Pompili M, Amore M, et al. Sensory processing patterns, coping strategies, and quality of life among patients with unipolar and bipolar disorders. Rev Bras Psiquiatr 2016 Inpress. 